OPEN ACCESS

Edited by:

Yvonne Höller,

University of Akureyri, Iceland

Reviewed by:

István Fekete,

University of Debrecen, Hungary

Simona Lattanzi,

Marche Polytechnic University, Italy

*Correspondence:

Sheng $\mathrm{Li}$

lisheng_1996@163.com

Qingshan Wang

wangq4@126.com

Jie Zhao

zhaoj@dmu.edu.cn

Specialty section: This article was submitted to

Epilepsy,

a section of the journal

Frontiers in Neurology

Received: 01 July 2021 Accepted: 05 November 2021 Published: 03 December 2021

Citation

Hou L, Peng B, Zhang D, Yang J, Wang Y, Tong L, Li S, Wang $Q$ and Zhao J (2021) Clinical Efficacy and Safety of Lacosamide as an Adjunctive Treatment in Adults With Refractory Epilepsy. Front. Neurol. 12:712717. doi: 10.3389/fneur.2021.712717

\section{Clinical Efficacy and Safety of Lacosamide as an Adjunctive Treatment in Adults With Refractory Epilepsy}

\author{
Liyan Hou ${ }^{1}$, Bingjie Peng ${ }^{2}$, Defu Zhang ${ }^{3}$, Jingjing Yang ${ }^{4}$, Ying Wang ${ }^{4}$, Li Tong ${ }^{1}$, \\ Sheng $\mathrm{Li}^{2,5 *}$, Qingshan Wang ${ }^{1,5 *}$ and Jie Zhao ${ }^{5 *}$
}

${ }^{1}$ School of Public Health, Dalian Medical University, Dalian, China, ${ }^{2}$ Department of Biochemistry and Molecular Biology, Dalian Medical University, Dalian, China, ${ }^{3}$ Office of Academic Affairs, Dalian Medical University, Dalian, China, ${ }^{4}$ Department of Neurology, The First Affiliated Hospital of DaLian Medical University, Dalian, China, ${ }^{5}$ National-Local Joint Engineering Research Center for Drug-Research and Development (R\&D) of Neurodegenerative Diseases, Dalian Medical University, Dalian, China

Background: Lacosamide (LCM), a novel AED (antiepileptic drug), was used as an adjunctive treatment in patients with partial-onset seizures or without secondary generalization. However, no meta-analysis was performed to evaluate the efficacy of LCM as an adjunctive treatment in post-marketing clinical studies.

Aims: To assess the safety and efficacy of LCM as an adjunctive treatment in adults with refractory epilepsy, a systematic review and meta-analysis of randomized controlled trials (RCTs) and real-world studies were performed.

Methods: All studies were identified from electronic databases. Both RCTs and observational prospective studies were included. Primary outcomes included responder rate, adverse effects (AEs) and withdraw rate. The pooled rates (PR) with their corresponding 95\% confidence intervals $(\mathrm{Cl})$ were calculated. Publication bias was assessed with Begg's or Egger's tests.

Results: Total 16 studies (3,191 patients) including 5 RCTs and 11 real-word studies were enrolled. The pooled 50\% responder rate and seizure-free rate were $48 \%$ (95\% Cl: $0.42,0.54)$ and $9 \%(95 \% \mathrm{Cl}: 0.06,0.11)$ in all studies, respectively. Subgroup analysis showed that the pooled $50 \%$ responder rate were $53 \%(95 \% \mathrm{Cl}: 0.44,0.62)$ from observational studies and $38 \%(95 \% \mathrm{Cl}: 0.35,0.42)$ from RCTs, respectively; the pooled seizure-free rate were $13 \%(95 \% \mathrm{Cl}: 0.09,0.18)$ from observational studies and $4 \%$ (95\% Cl: $0.06,0.11)$ from RCTs, respectively. Similar incidence of AEs were reported in real-world studies $(0.57,95 \% \mathrm{Cl}: 0.43,0.72)$ and RCTs $(0.59,95 \% \mathrm{Cl}: 0.42-0.76)$. Finally, a total of $13 \%(95 \% \mathrm{Cl}: 0.09,0.16)$ and $13 \%(95 \% \mathrm{Cl}: 0.08,0.16)$ of all patients prescribed with LCM was withdrawn in RCTs and real-world studies, respectively, due 
to the occurrence of AEs. Furthermore, similar to the $50 \%$ responder rate, seizure-free rate, incidence of $A E s$ and withdraw rate were reported at 6-month or at least 12-month of LCM adjunction. Publication bias was not detected in these studies.

Conclusions: Our results revealed that LCM adjunctive therapy even with long-term treatment was efficacious and well tolerated in adults with refractory epilepsy.

Keywords: antiepileptic drugs, seizures, add-on therapy, meta-analysis, randomized controlled trial, real-world study

\section{INTRODUCTION}

Epilepsy is one of the most common neurological disorders with high prevalence and affects approximately $0.5-1 \%$ of the general population worldwide (1). Although many patients with epilepsy are able to achieve seizure control with anti-epileptic drugs (AEDs) treatment, $20-30 \%$ of these patients not only continue to suffer from ongoing seizures and but also experience adverse effects from the treatment (2). Patients who are unable to obtain satisfactory seizure remission on two or more different AEDs therapies are usually referred as having refractory epilepsy (3). Studies have shown that refractory epilepsy is associated with increased morbidity and mortality, serious psychosocial consequences, social impairments, which limit employment and also decrease life quality (4). Despite of rapid development of new therapeutic strategies, AEDs still play important roles in managing epilepsy in clinic.

Lacosamide (LCM), a novel antiseizure medication, was approved in 2008 by US FDA and European Medicines Agency (EMA) as an adjunctive treatment in adults with partial-onset seizures or without secondary generalization (5). In contrast to classical sodium channel-blocking AEDs that act preferentially on the fast inactivation component by shifting the voltage dependence of inactivation to more hyperpolarized potentials, LCM selectively enhances slow inactivation of voltage-gated sodium channels through binding to the collapsin response mediator protein $2(6,7)$. In 2013, a meta-analysis of randomized controlled trials (RCTs) showed that LCM appears to be a safe, efficacious and cost-effective adjunctive therapy for partial-onset epileptic seizures in adults (8). Recently, Babar and colleagues also evaluated the efficacy and tolerability of LCM as an addon therapy for children and adults with drug-resistant focal epilepsy (9). However, previous two studies only included RCTs and the trial duration ranged from 24-28 weeks, the longerterm efficacy (LCM treatment $\geq 6$ months) remains unknown. Although RCTs are the gold standard for evaluation of antiseizure medication treatment, there is a critical role for observational studies in extending what we learn from initial trials. In additional to confirming the consistency of efficacy and safety of antiseizure medication treatment when applied to routine practice, observational studies in the real-life clinical practice can ascertain treatment patterns (adoption, dosing, AEs, and so on) and gather data from populations not included in the RCTs (e.g., brain tumor-related epilepsy, nocturnal seizures). Recent observational studies reporting on post-marking clinical experience with LCM provide supplementary information revealed both benefits and adverse effects (AEs) of LCM as an adjunctive treatment in patients with refractory epilepsy in dayto-day clinical practice $(10,11)$. To date, no meta-analysis was performed to evaluate the efficacy of LCM as an adjunctive treatment in real-world observational studies that has played important roles in exploring biological efficacy of therapeutic intervention (12). Therefore, the efficacy, safety and tolerability of LCM should be further validated, especially in refractory epilepsy by enrolling both RCTs and real-world observational studies with different time-period treatment.

The present study is therefore designed to carry out a comprehensive meta-analysis to assess the safety, efficacy and AEs of LCM as an adjunctive treatment for patients with refractory epilepsy by summarizing current evidences derived from updated RCTs and high-quality observational studies with different time-period treatment, providing useful information for developers and prescribers in routine clinical practice.

\section{METHODS}

\section{Systematic Literature Search}

Our meta-analysis adhered to the Preferred Reporting Items for Systematic Reviews and Meta-analyses (PRISMA) principles (13). All relevant articles identified through electronic searching of PubMed, Embase, Chinese National Knowledge Infrastructure, and Wanfang (China) databases up to May 18, 2020. The following search strategy was used: (drug-resistant epilepsy OR refractory epilepsy OR uncontrolled seizure OR Focal epilepsy OR generalized epilepsy OR partial-onset seizures) AND (Lacosamide) in title/abstract. The subjects of studies were defined as human, and the languages of articles were limited to English and Chinese because the reviewers are fluent in both languages. If more than one article were published using the same data, only the study with largest sample size was included. Additionally, a manual search was also conducted to retrieve additional literature from the reference lists of relevant review article.

\section{Inclusion and Exclusion Criteria}

Selection criteria of RCTs or observational studies included in our meta-analysis were: 1 ) subjects confirmed to adults (age $\geq 16$ years); 2) adult participants with focal seizures are unable to obtain satisfactory seizure remission at least 2 AEDs according to the guideline of International League Against Epilepsy (ILAE); 3) provision of at least two outcomes of interest from $50 \%$ reduction in seizure frequency comparing to baseline, seizure-free rate and 
articles identified through database search $(n=825)$

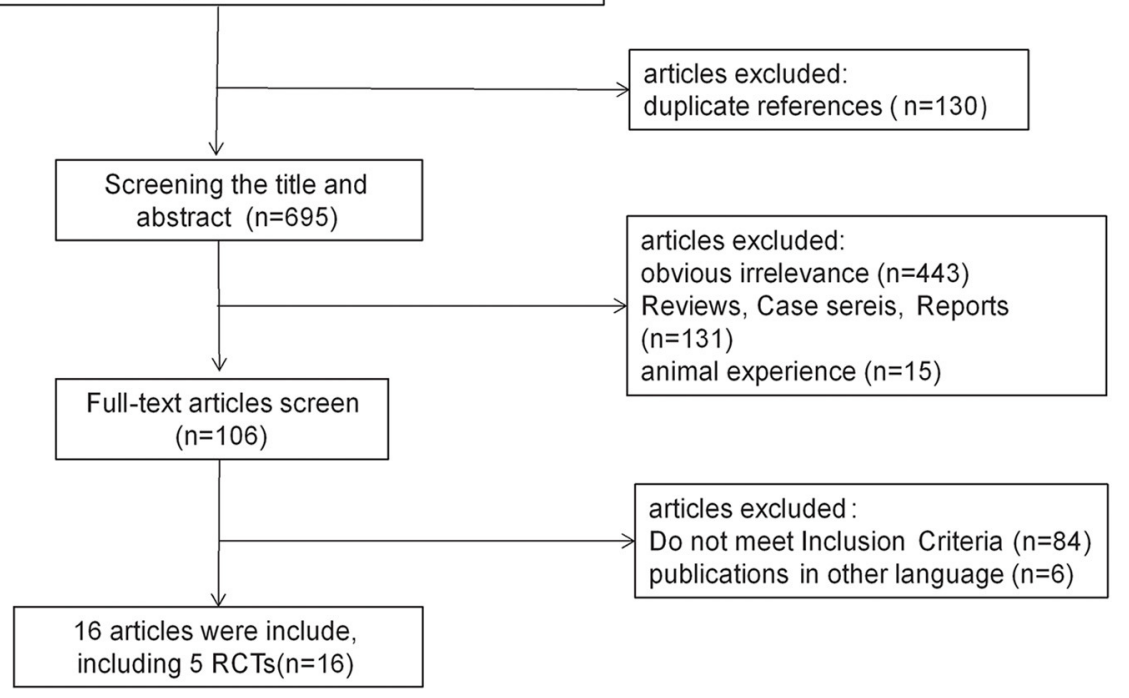

FIGURE 1 | Flow diagram of study selection process.

side effects; 4) the treatment duration (excluding titration) was more than 8-weeks, a time that is considered to represent the minimum period to differentiate change in seizure frequency; 5) written in English or Chinese with full text available; 6) sample size more than 10. The following studies were excluded: 1) animal-based studies; 2) subjects were children and adolescents (age $<16$ years); 3) studies written in a language other than English or Chinese; 4) studies without original data such as comments, letters, reviews.

\section{Date Extraction and Outcome Measures}

Two authors (Bingjie $\mathrm{P}$ and $\mathrm{Li} \mathrm{T}$ ) independently assessed the studies according to the inclusion/exclusion criteria and any discrepancies were resolved by discussion with senior authors (Qingshan W). Data collection was performed by two independent investigators (Jingjing Y and Ying W). The extracted information included the first author, publication year, number of participants, number of patients (number of patients in each group for RCTs), patients' demographic characteristics, duration of the follow-up, dosage of LCM, and outcome data.

In this meta-analysis, two clinical efficacy outcomes were assessed: 1) 50\% responder rate (responders were defined as those who experienced a $50 \%$ or greater reduction in seizure frequency in the treatment period compared with baseline period); 2) seizure-free rate (seizure freedom was defined as proportion of patients that were seizure-free during treatment and followup period).

Two clinical safety outcomes were assessed in this metaanalysis: 1) AEs (proportion of patients experiencing any of the common AEs, such as ataxia, dizziness, fatigue, headache, nausea, and somnolence); 2) withdrawal rate due to AEs (proportion of patients with treatment withdrawal due to adverse effects of LCM).

\section{Date Synthesis and Analysis}

The quantitative meta-analysis was performed using STATA version 12.0 (StataCorp LP, College Station, TX). The pooled rates (RRs) with their corresponding 95\% CIs were calculated to assess the clinical efficacy and safety outcomes. Subgroup analyses were performed based on type of study (RCTs and observational studies) to assess the safety and efficacy of LCM as an adjunctive treatment in adults with refractory epilepsy. Considering long-term adjunctive LCM treatment (at least 12 months treatment) might cause heterogeneity, subgroup analyses were performed in observed studies. For both analysis models, the between-study heterogeneity was assessed using the Cochran's Q and $\mathrm{I}^{2}$ statistics (14), and a value of $I^{2}>50 \%$ was considered significant heterogeneity $(15,16)$. A random-effects model was used to calculate pooled RR in the presence $(P \leq$ $0.10)$ of heterogeneity (16); otherwise, the fixed-effects model was used. Begg's and Egger's tests were also applied to quantify potential publication bias, and a value of $P<0.05$ was considered statistically significant (15).

\section{RESULTS}

\section{Literature Search}

A total of 825 relevant studies were identified. After removing duplicates by endnote software, 695 citations were independently undergone abstract review and 106 of them were considered potentially relevant trials. Among the 106 full-text articles, eighty-four studies did not meet the inclusion criteria since they were conducted on children, healthy volunteers, or indications other than epilepsy. Six studies published in other languages were also excluded. Finally, 16 studies met the inclusion criteria and were enrolled. A diagram summarizing the process of study selection is shown in Figure 1. 
TABLE 1 | Characteristics of the randomized controlled trials included in the present meta-analysis.

\begin{tabular}{|c|c|c|c|c|c|c|c|c|c|c|}
\hline \multirow[t]{2}{*}{ References } & \multirow[t]{2}{*}{ Study design } & \multirow{2}{*}{$\begin{array}{l}\text { Number and type of } \\
\text { concomitant AEDs }\end{array}$} & \multirow{2}{*}{$\begin{array}{c}\text { Gender } \\
\text { (male/female) }\end{array}$} & \multirow{2}{*}{$\begin{array}{l}\text { Age, years } \\
(\text { mean } \pm \text { SD) }\end{array}$} & \multirow{2}{*}{$\begin{array}{c}\text { Duration of } \\
\text { epilepsy } \\
\text { (Year/Month } \pm \text { SD) }\end{array}$} & \multirow{2}{*}{$\begin{array}{c}\text { Duration of } \\
\text { treatment }\end{array}$} & \multirow{2}{*}{$\begin{array}{l}\text { LCM dosage } \\
\text { (mg/day) or } \\
\text { Placebo }\end{array}$} & \multicolumn{3}{|c|}{ Seizure classification, $\mathbf{n}(\%)$ patients } \\
\hline & & & & & & & & $\begin{array}{l}\text { Simple } \\
\text { partial } \\
\text { seizure }\end{array}$ & $\begin{array}{l}\text { Complex } \\
\text { partial } \\
\text { seizure }\end{array}$ & $\begin{array}{l}\text { Secondary } \\
\text { partial } \\
\text { attack }\end{array}$ \\
\hline $\begin{array}{l}\text { Ben-Menachem } \\
\text { et al. (17) }\end{array}$ & $\begin{array}{l}8 w \text {-baseline } \\
6 w \text {-titration period } \\
12 w \text {-maintenance } \\
\text { period }\end{array}$ & $\begin{array}{l}\text { 1-2/ CBZ, } \\
\text { LTG, } \\
\text { LEV, } \\
\text { OXC, et al. }\end{array}$ & $\begin{array}{l}47 / 50 \\
46 / 61 \\
53 / 55 \\
45 / 61\end{array}$ & $\begin{array}{l}38.9 \pm 11.11 \\
39.9 \pm 11.71 \\
41.2 \pm 11.61 \\
39.4 \pm 10.53\end{array}$ & $\begin{array}{l}24.6 \pm 11.77 \\
25.1 \pm 12.89 \\
24.7 \pm 13.08 \\
23.6 \pm 12.74\end{array}$ & $26 w$ & $\begin{array}{l}\text { Placebo } \\
200 \mathrm{mg} \\
400 \mathrm{mg} \\
600 \mathrm{mg}\end{array}$ & $\begin{array}{l}33(34) \\
48(45) \\
41(38) \\
50(47)\end{array}$ & $\begin{array}{c}83(86) \\
101(94) \\
94(87) \\
96(91)\end{array}$ & $\begin{array}{l}73(75) \\
79(74) \\
77(71) \\
70(66)\end{array}$ \\
\hline Halasz et al. (19) & $\begin{array}{l}8 w \text {-baseline } \\
4 w \text {-titration period } \\
12 w \text {-maintenance } \\
\text { period } \\
2 w \text {-transition } \\
\text { period }\end{array}$ & $\begin{array}{l}\text { 1-3/ CBZ, } \\
\text { LEV, } \\
\text { VPA,; } \\
\text { TPM, et al. }\end{array}$ & $\begin{array}{l}91 / 72 \\
90 / 73 \\
69 / 90\end{array}$ & $\begin{array}{l}38.5 \pm 10.93 \\
36.9 \pm 11.70 \\
37.9 \pm 12.96\end{array}$ & $\begin{array}{l}21.1 \pm 12.23 \\
22.9 \pm 12.30 \\
22.8 \pm 13.15\end{array}$ & $26 w$ & $\begin{array}{l}\text { Placebo } \\
200 \mathrm{mg} \\
400 \mathrm{mg}\end{array}$ & $\begin{array}{l}61(37.4) \\
67(41.1) \\
58(36.5)\end{array}$ & $\begin{array}{l}138(84.7) \\
142(87.1) \\
146(91.8)\end{array}$ & $\begin{array}{l}130(79.8) \\
125(76.7) \\
127(79.9)\end{array}$ \\
\hline Chung et al. (20) & $\begin{array}{l}8 w \text {-baseline } \\
6 w \text {-titration period } \\
12 w \text {-maintenance } \\
\text { period } \\
2 w- \\
\text { transition period }\end{array}$ & 1-3/LEV, CBZ, LGT, et al. & $\begin{array}{c}49 / 55 \\
104 / 100 \\
47 / 50\end{array}$ & $\begin{array}{l}38.1 \pm 11.96 \\
39.1 \pm 12.37 \\
36.8 \pm 11.76\end{array}$ & $\begin{array}{l}25.4 \pm 13.34 \\
24.5 \pm 13.16 \\
23.4 \pm 13.28\end{array}$ & $28 w$ & $\begin{array}{l}\text { Placebo } \\
400 \mathrm{mg} \\
600 \mathrm{mg}\end{array}$ & $\begin{array}{l}41(39.4) \\
73(36.3) \\
35(36.1)\end{array}$ & $\begin{array}{r}86(82.7) \\
170(84.6) \\
75(77.3)\end{array}$ & $\begin{array}{l}45(43.3) \\
84(41.8) \\
47(48.5)\end{array}$ \\
\hline Hong et al. (18) & $\begin{array}{l}8 w \text {-baseline } \\
4 w \text {-titration period } \\
12 w \text {-maintenance } \\
\text { period } \\
2 w \text { - transition } \\
\text { period or } \\
3 w \text {-taper period }\end{array}$ & $\begin{array}{l}\text { 1-3/CBZ, } \\
\text { VPA, } \\
\text { OXC, } \\
\text { et al. }\end{array}$ & $\begin{array}{c}102 / 82 \\
94 / 89 \\
104 / 76\end{array}$ & $\begin{array}{l}31.8 \pm 12.0 \\
33.2 \pm 12.2 \\
32.3 \pm 11.9\end{array}$ & $\begin{array}{l}16.8 \pm 11.5 \\
18.3 \pm 10.9 \\
17.9 \pm 11.7\end{array}$ & $27 w$ & $\begin{array}{l}\text { Placebo } \\
200 \mathrm{mg} \\
400 \mathrm{mg}\end{array}$ & $\begin{array}{l}60(32.8) \\
64(35.2) \\
61(34.1)\end{array}$ & $\begin{array}{l}183(99.5) \\
169(92.3) \\
173(96.1)\end{array}$ & $\begin{array}{l}129(70.5) \\
114(62.6) \\
107(59.8)\end{array}$ \\
\hline Chung et al. (21) & $\begin{array}{l}4 w- \\
\text { increasing period } \\
12 w \text {-maintenance } \\
\text { period } \\
2 w \text {-reduction } \\
\text { period }\end{array}$ & $\begin{array}{l}\text { 1-4/ CBZ, } \\
\text { LEV, } \\
\text { OXC, } \\
\text { TMP, et al. }\end{array}$ & $\begin{array}{l}90 / 79 \\
97 / 75 \\
93 / 81\end{array}$ & $\begin{array}{l}30.54 \pm 12.04 \\
29.61 \pm 12.74 \\
30.50 \pm 11.18\end{array}$ & $\begin{array}{l}158.7 \pm 110.57 \mathrm{~m} \\
159.6 \pm 101.17 \mathrm{~m} \\
172.9 \pm 120.60 \mathrm{~m}\end{array}$ & $18 w$ & $\begin{array}{l}\text { Placebo } \\
200 \mathrm{mg} \\
400 \mathrm{mg}\end{array}$ & $\begin{array}{l}33(19.53) \\
36(20.93) \\
38(21.84)\end{array}$ & $\begin{array}{l}105(62.13) \\
102(59.30) \\
104(59.77)\end{array}$ & $\begin{array}{l}72(42.60) \\
68(39.53) \\
76(43.68)\end{array}$ \\
\hline
\end{tabular}

AEDs, anti-epileptic drugs; CBZ, Carbamazepine; VPA, valproic acid; LEV, levetiracetam; LTG, Lamotrigine; OXC, Oxcarbazepine; TPM, Topiramate; SD, standard deviation. 
TABLE 2 | Characteristics of the observational studies included in this meta-analysis.

\begin{tabular}{|c|c|c|c|c|c|c|c|c|c|c|c|c|}
\hline \multirow[t]{2}{*}{ References } & \multirow{2}{*}{$\begin{array}{l}\text { Number of } \\
\text { patients }\end{array}$} & \multirow{2}{*}{$\begin{array}{l}\text { Study } \\
\text { design }\end{array}$} & \multirow{2}{*}{$\begin{array}{l}\text { Type of } \\
\text { concomitant } \\
\text { AEDs }\end{array}$} & \multirow{2}{*}{$\begin{array}{c}\text { Gender } \\
\text { (male/female) }\end{array}$} & \multirow{2}{*}{$\begin{array}{l}\text { Age }[\text { mean } \pm \mathrm{SL} \\
\text { or mean } \\
\text { (range)] }\end{array}$} & \multirow{2}{*}{$\begin{array}{l}\text { Time since } \\
\text { diagnosis, } \\
\text { years } \\
\text { (mean } \pm \text { SD) }\end{array}$} & \multirow{2}{*}{$\begin{array}{l}\text { Duration } \\
\text { of follow-up } \\
\text { (Months) }\end{array}$} & \multirow{2}{*}{$\begin{array}{l}\text { LCM dosage } \\
\text { (mg/day) }\end{array}$} & \multicolumn{4}{|c|}{ Seizure classification, number of patients } \\
\hline & & & & & & & & & A & B & C & D \\
\hline $\begin{array}{l}\text { Kleist et al. } \\
\text { (29) }\end{array}$ & 80 & Add-on & $\begin{array}{l}\text { VPA, LEV, } \\
\text { LTG, et al. }\end{array}$ & $51 / 29$ & $36.2 \pm 12.8$ & $27.9 \pm 13.9$ & 24 months & $300-400 \mathrm{mg}$ & \multicolumn{4}{|c|}{ patients with intellectual disability } \\
\hline $\begin{array}{l}\text { Zadeh et al. } \\
\text { (26) }\end{array}$ & 456 & $\begin{array}{l}\text { Frist add-on } \\
\text { Later add-on }\end{array}$ & $\begin{array}{l}\text { VPA, CBZ, } \\
\text { OXC, et al. } \\
\text { VPA, CBZ, } \\
\text { OXC, et al. }\end{array}$ & $\begin{array}{c}53 / 43 \\
180 / 180\end{array}$ & $\begin{array}{l}41 \pm 17.08 \\
38 \pm 12.34\end{array}$ & $\begin{array}{c}1.1 \pm 2.22 \\
22.9 \pm 13.11\end{array}$ & 24 months & $\begin{array}{l}300-400 \mathrm{mg} \\
300-400 \mathrm{mg} ;\end{array}$ & $\begin{array}{l}\text { SPS(29) } \\
\text { SPS(112) }\end{array}$ & $\begin{array}{l}\text { CPS(57) } \\
\text { CPS(259) }\end{array}$ & $\begin{array}{l}\text { sGS(69) } \\
\text { sGS(241) }\end{array}$ & GS:(3) \\
\hline $\begin{array}{l}\text { García- } \\
\text { Morales et al. } \\
\text { (30) }\end{array}$ & 60 & Add-on & $\begin{array}{l}\text { LEV, CBZ, } \\
\text { LTG, et al. }\end{array}$ & $28 / 32$ & 38.3 & 27.2 & 24 months & $200-500 \mathrm{mg}$ & NS(17) & $\mathrm{DS}(43)$ & & \\
\hline $\begin{array}{l}\text { Wehner et al. } \\
\text { (24) }\end{array}$ & 25 & Add-on & $\begin{array}{l}\text { LTG, LEV, } \\
\text { CBZ and ZNS }\end{array}$ & $12 / 13$ & $16-74$ & NA & 6 months & $400 \mathrm{mg}$ & \multicolumn{4}{|c|}{ Putative etiology of focal epilepsy } \\
\hline $\begin{array}{l}\text { Rocamora } \\
\text { et al. (11) }\end{array}$ & 49 & Add-on & LEV & $24 / 25$ & $39.5 \pm 15.5$ & $17.1 \pm 14.6$ & 6 months & $200-400 \mathrm{mg}$ & SPS(20) & CPS(34) & sGTCS(23) & - \\
\hline $\begin{array}{l}\text { Flores et al. } \\
\text { (27) }\end{array}$ & 285 & Add-on & $\begin{array}{l}\text { CBZ, LEV, } \\
\text { et al. }\end{array}$ & 199/204 & $41 .(17-82)$ & NA - & $\begin{array}{l}\text { Mean } 11.6 \\
\text { months }\end{array}$ & $25-700 \mathrm{mg}$ & LCE(39) & SGE(7) & SPE(263) & $\mathrm{UC}(11)$ \\
\hline $\begin{array}{l}\text { McGinty et al. } \\
\text { (10) }\end{array}$ & 100 & Add-on & $\begin{array}{l}\text { LEV, VPA, } \\
\text { CBZ, et al. }\end{array}$ & $51 / 49$ & $18-84$ & $-N A$ & 24 months & $50-300 \mathrm{mg}$ & GGE(7) & LRE760 & $\operatorname{SGE}(11)$ & UC(6) \\
\hline $\begin{array}{l}\text { Maschio et al. } \\
\text { (23) }\end{array}$ & 25 & Add-on & LEV & $18 / 7$ & $22-74$ & NA & 6 months & $100-400 \mathrm{mg}$ & SPS(9) & CPS(8) & sGS(8) & - \\
\hline $\begin{array}{l}\text { Stephen et al. } \\
\text { (22) }\end{array}$ & 113 & Add-on & $\begin{array}{l}\text { CBZ, LTG, } \\
\text { OXC, et al. }\end{array}$ & $57 / 56$ & $18-74$ & 4 & 6 months & 200-400mg & POS & & & \\
\hline $\begin{array}{l}\text { Husain et al. } \\
\text { (28) }\end{array}$ & 309 & Add-on & $\begin{array}{l}\text { CBZ, OXC, } \\
\text { LEV, et al. }\end{array}$ & $162 / 146$ & $38 . \pm 12.46$ & $23.8 \pm 12.97$ & 12 months & $100-600 \mathrm{mg}$ & Pos & & & \\
\hline IJff et al. (25) & 33 & Add-on & - & $9 / 24$ & $37 \pm 14.5$ & NA & $\begin{array}{l}\text { Mean } 7 \\
\text { months }\end{array}$ & $100-600 \mathrm{mg}$ & Cryptogen & Symptoma & & - \\
\hline
\end{tabular}

AEDs, anti-epileptic drugs; SD, standard deviation; NS (the nocturnal seizure group); NA, not available; SPS, simple partial seizure; CPS, complex partial seizures; sGS, secondarily generalized seizures; GS, generalized seizures; NS, nocturnal seizure: DS, diurnal seizure; POS, partial-onset seizures; sGTCS, secondarily generalized tonic-clonic seizures; GGE, genetic generalized epilepsy; LRE, localization-related epilepsy (focal epilepsy); SGE, symptomatic generalized epilepsy; IGE, idiopathic generalized epilepsy; UC, unclassified; SPE, symptomatic generalized epilepsy; ID, intellectual disability. Abbreviation of concomitant drugs: VPA, valproic acid; LEV, levetiracetam; CBZ, Carbamazepine; LTG, Lamotrigine; OXC, Oxcarbazepine, TPM, Topiramate; ZNS, Zonisamide. add-on: The 'first add-on' cohort of patients received lacosamide as their first adjunctive treatment after a first monotherapy, while the 'later add-on' cohort had previously been treated with at least two prior AED treatment regimens before adding lacosamide. 


\section{Characteristics of the Enrolled Studies}

The total of 16 studies enrolled in this meta-analysis included 5 RCTs (one paper published in Chinese) and 11 real-world observational studies $(10,11,17-30)$. The baseline characteristics of RCTs were summarized in Table 1. All studies were published from 2007 to 2016. The age of patients was restricted to over 16 years in four studies and over 18 years in one study. All enrolled patients have had partial-onset seizures for at least the last 2 years despite prior therapy with at least 2 AEDs. In the 5 RCTs, 1,642 patients received LCM as an adjunctive treatment for refractory epilepsy. LCM at dosage of 200, 400, or $600 \mathrm{mg}$ /day was administered with fixed titration schedule. All trials had a 12-week maintenance period and a 4-6 week titration period.

The main characteristics of observational studies were summarized in Table 2. Eleven real-world observational studies published from 2012 to 2018 were included. A total 1,549 patients with LCM as an adjunctive treatment for refractory epilepsy were enrolled. In addition to LCM, all patients were treated with one to three other AEDs. The duration of LCM treatment was ranged from 6 to 24 months. Since the data in one study were provided by "first add-on" and "later add-on" cohort, we analyzed the data separately and considered them to be separate studies.

\section{Clinical Efficacy Outcomes Meta-Analysis}

All studies provided data regarding seizure-frequency reduction from baseline $\geq 50 \%$ in response to LCM adjunction. Due to substantial heterogeneity (heterogeneity: $P=0.00, I^{2}=90.4 \%$ ), a random-effects model was used to calculate pooled RR and corresponding $95 \% \mathrm{CI}$. The pooled $50 \%$ responder rate was $48 \%$ (95\% CI: 0.42, 0.54) (Figure 2A) in all studies. Our subgroup analysis showed that the pooled $50 \%$ responder rate were $53 \%$ (95\% CI: $0.44,0.62)$ from observational studies and 38\% (95\% CI: $0.35,0.42)$ from RCTs, respectively. Since the data on $50 \%$ responder rate were provided at different time points (6- \& 12-month after LCM adjunction) in observational studies, they were further analyzed separately. The $50 \%$ responder rates after 6-month of LCM adjunction, ranging from 0.32 to 0.86 , was available for analysis in 1,101 patients. The pooled $50 \%$ responder rate after 6-month of LCM adjunction was 53\% (95\%CI: 0.41 , $0.65 ; P=0.000)$ (Figure 2B) with high heterogeneity $\left(I^{2}=92.9 \%\right.$, $P=0.000)$. Furthermore, the $50 \%$ responder rates for longterm (at least 12 months) of LCM adjunction was analyzed from the date provided by 448 patients in 5 observational studies and a rangement from 0.47 to 0.64 was observed. The pooled $50 \%$ responder rate for long-term of LCM adjunction was 53\% (95\%CI: $0.44,0.62 ; P=0.000)$ with high heterogeneity $\left(I^{2}=\right.$ $91.2 \%, P=0.000$ ) (Figure 2B). No publication bias was seen based on Begg's $(p=0.06)$. Fifteen studies provided data of seizure-free rate in response to LCM adjunction. The overall pooled seizure-free rate was 9\% (95\% CI: 0.06, 0.11) (Figure 3A) with high heterogeneity $\left(I^{2}=87.4 \%, P=0.000\right)$. Our subgroup analysis showed that the pooled seizure-free rate were $13 \%$ (95\% CI: $0.09,0.18)$ from observational studies and 4\% (95\% CI: $0.06,0.11)$ from RCTs, respectively. Nine observational studies provided data of seizure-free rate in response to LCM adjunction. The data regarding seizure-free rate (ranged from 0.07 to 0.32 ) at 6 -month of LCM adjunction, were provided in
6 studies (including 1,068 patients). The pooled seizure-free rate at 6-month of LCM adjunction was 14\% (95\%CI: $0.09,0.19$; $P=0.000)$ with high heterogeneity $\left(I^{2}=78.4 \%, P=0.000\right)$. Furthermore, the seizure-free rate (ranged from 0.03 to 0.19 ) for long-term of LCM adjunction, was analyzed in 3 studies including 411 patients. The pooled seizure-free rate for longterm of LCM adjunction was 12\% (95\%CI: 0.01, 0.24; $P=0.000)$ (Figure 3B) with high heterogeneity $\left(I^{2}=91.4 \%, P=0.000\right)$. Begg's $(P=1)$ and Egger's tests $(P=0.98)$ revealed no significant publication bias among the included studies.

\section{Clinical Safety Outcomes Meta-Analysis}

Twelve studies reported the occurrence of AEs, although most AEs were mild and transients. Due to a significant heterogeneity (heterogeneity $I^{2}=98.9 \%, P=0.00$ ), a random-effects model was used to calculate pooled RR and its corresponding 95\% CI.

The polled incidence of AEs in 12 studies was 57\% (95\%CI: $0.43,0.72 ; P=0.00$ ) (Figure 4A). Subgroup analysis showed that the pooled incidence of AEs were 59\% (95\% CI: 0.42, 0.76) from observational studies and 57\% (95\% CI: $0.43,0.72)$ from RCTs, respectively (Figure 4A). Subsequently, the incidence of AEs was analyzed in 1,441 patients after 6- and 12-month of LCM adjunction. The incidences of AEs, ranged from 0.49 to 0.73 , after 6-month of LCM adjunction were provided in 3 studies including 933 patients. The pooled incidence of AEs at 6-month of LCM adjunction was $61 \%(95 \% \mathrm{CI}: 0.48,0.74 ; P=0.00)$ with high heterogeneity $\left(I^{2}=92.8 \%, P=0.00\right)$. Similarly, the incidence of AEs, ranged from 0.38 to 0.94 , for long-term of LCM adjunction was available in 3 studies including 448 patients. The pooled incidence of AEs for long-term of LCM adjunction was 55\% (95\%CI: $0.42,0.76 ; P=0.00)$ with high heterogeneity $\left(I^{2}=\right.$ 98.9\%, $P=0.00$ ) (Figure 4B).

Fifteen studies reported the withdraw rate due to AEs. The polled withdrawal rate in 15 studies was $13 \%$ (95\% CI: $0.10,0.16)$. Subgroup analysis showed that the pooled withdrawal rate due to AEs were 13\% (95\% CI: 0.09, 0.16) from observational studies and 13\% (95\% CI: 0.08, 0.18) from RCTs, respectively (Figure 5A). Further analyses revealed that the withdrawal rate after 6 and after 12-month of LCM adjunction, were 15.5\% (95\% CI: 0.134 , 0.177 ) and $9.7 \%$ (95\% CI: 0.039, 0.155), respectively (Figure 5B). Publication bias was not detected based on Begg's test (incidence of adverse events, $p=0.2$; withdraw rate, $p=0.2$ ).

\section{Discussion}

To our best knowledge, this meta-analysis, for the first time, provided the comprehensive and explicit assessment of the safety and efficacy of LCM as an adjunctive treatment in adults with refractory epilepsy by using both RCTs and real-world observational studies. This study analyzed pooled data from 3,191 patients in 5 RCTs and 11 observational studies, providing practical details on how each agent licensed for developers and prescribers in daily clinical practice.

The 50\% responder rate and seizure-free rate were pooled to assess the efficacy of LCM. Pooled data from 3,191 patients with LCM as an adjunctive treatment for refractory epilepsy indicated that LCM adjunction was more likely to achieve 
A Pooled effect of $50 \%$ responder rate by study type

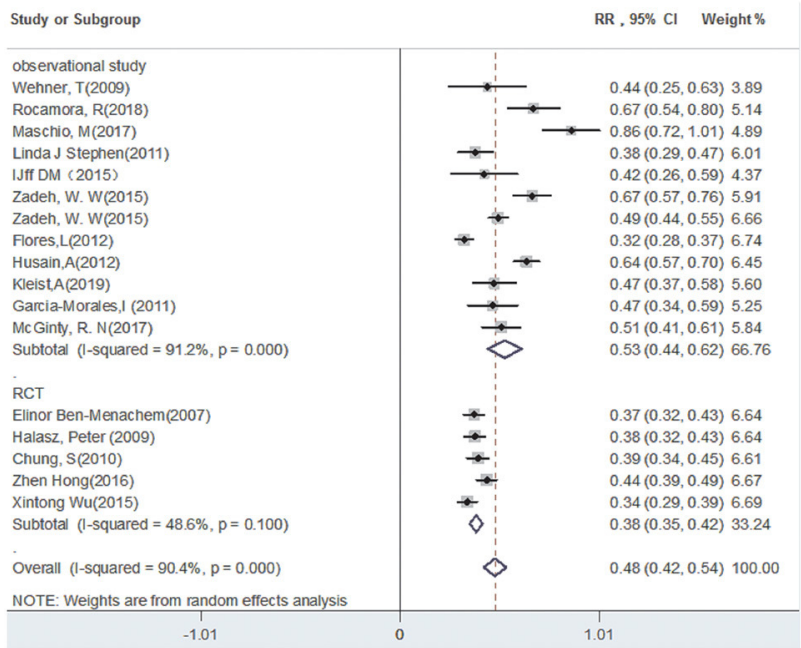

B Subgroup analysis of $50 \%$ responder rate in observational studies

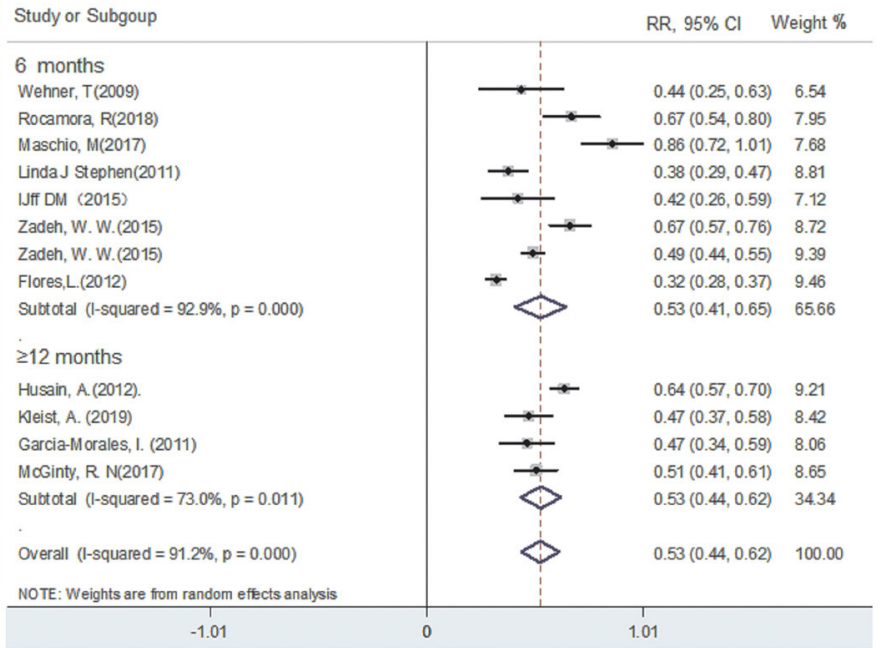

FIGURE 2 | Meta-analysis of 50\% responder rate. (A) Poole effect of 50\% responder rate by study type. (B) Subgroup analysis of $50 \%$ responder rate in observational studies.

\section{Meta-analysis of seizure-free rate}

A Pooled effect of seizure-free rate by study type

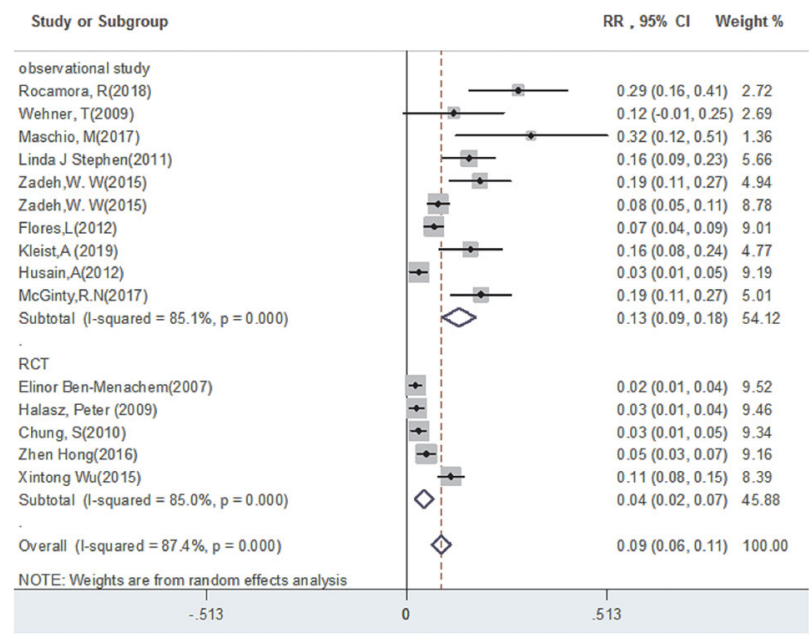

B Subgroup analysis of seizure-free rate in observational studies

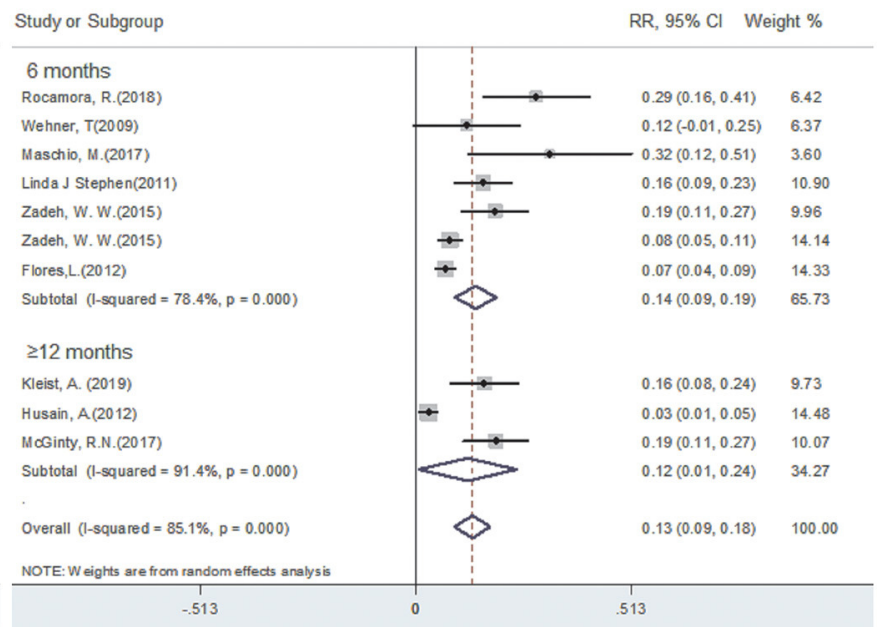

FIGURE 3 | Meta-analysis of seizure-free rate. (A) Poole effect of seizure-free rate by study type. (B) Subgroup analysis of seizure-free rate in observational studies.

seizure control. Our findings are similar to those of previous reports, in which LCM was considered to superior to placebo in preventing seizures $(8,31)$. The clinical efficacy outcomes of LCM adjunction between RCTs and observational studies were further compared. The pooled result from RCTs revealed that $50 \%$ responder rate was $38 \%$. By contrast, $53 \%$ of patients in real-world studies achieved a $\geq 50 \%$ reduction in seizure frequency at a short period of time ( $<12$ months). Interestingly, the pooled $50 \%$ responder rate in real-world studies was still as high as $53 \%$ when patients treated with LCM at least 12 months, indicating that LCM appears to be effective for a long period of time. As for seizure freedom, our cumulative analysis revealed that $4 \%$ of patients became seizure-free following LCM adjunction in RCTs, whereas $13 \%$ of subjects achieved seizure 


\section{Meta-analysis of incidence of adverse events}

\section{A Pooled effect of incedence of adverse events by study type}

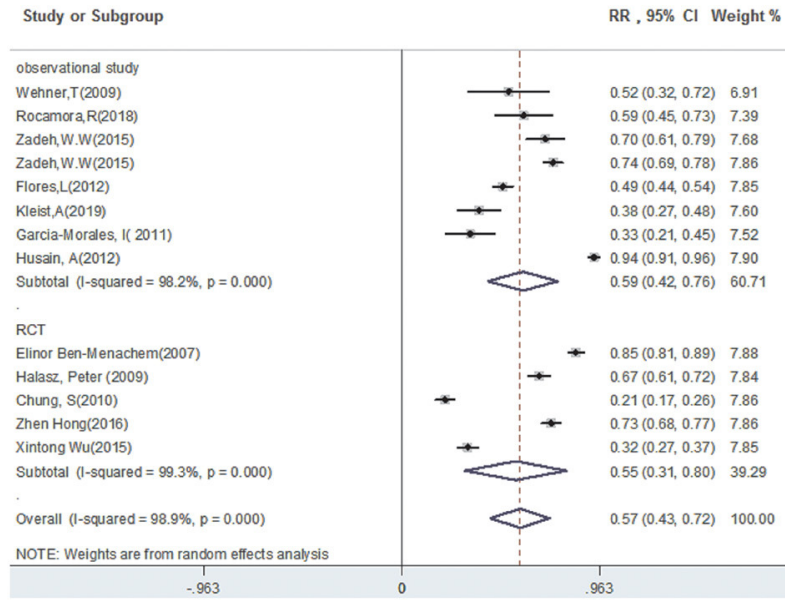

B Subgroup analysis of incidence of adverse events in observatioanl studies

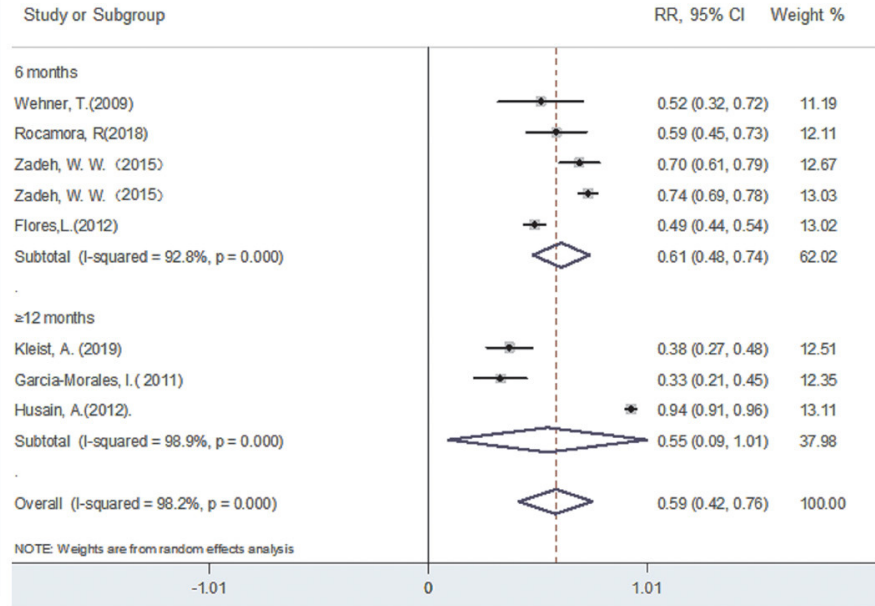

FIGURE 4 | Meta-analysis of incidence of adverse events. (A) Poole effect of incidences of adverse effects by study type. (B) Subgroup analysis of incidences of adverse effects in observational studies.

\section{Meta-analysis of withdraw rate due to adverse events}

A Pooled effect of withdraw rate due to advserse events by study type

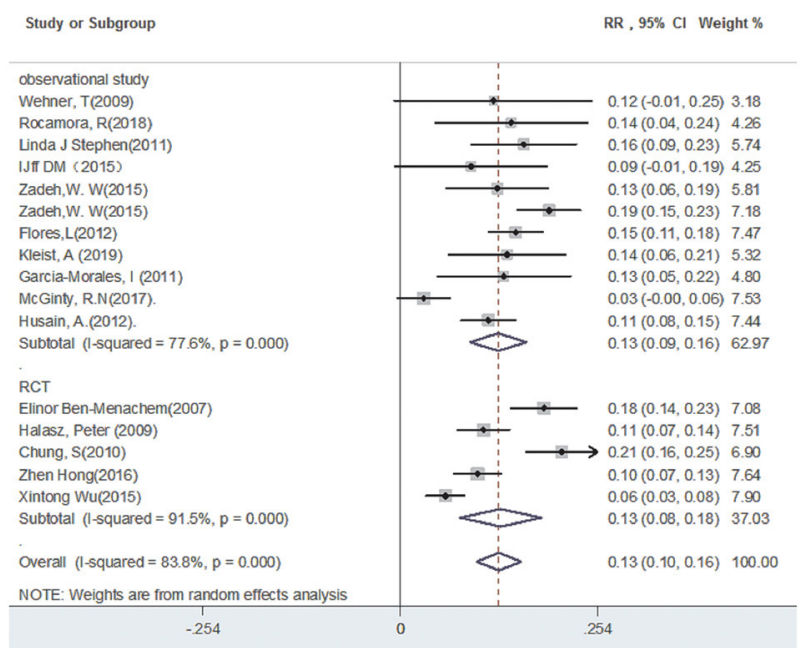

B Subgroup analysis of withdraw rate due to adverse events in obervational studies

\begin{tabular}{|c|c|c|c|}
\hline Study or Subgroup & & $\mathrm{RR}, 95 \% \mathrm{Cl}$ & leight \% \\
\hline 6 months & & & \\
\hline Wehner, T.(2009) & & $0.12(-0.01,0.25)$ & 5.04 \\
\hline Rocamora, R(2018) & & $0.14(0.04,0.24)$ & 6.75 \\
\hline Linda J Stephen(2011) & & $0.16(0.09,0.23)$ & 9.12 \\
\hline IJff DM. (2015) & & $0.09(-0.01,0.19)$ & 6.75 \\
\hline Zadeh, W. W.(2015) & & $0.13(0.06,0.19)$ & 9.23 \\
\hline Zadeh, W. W.(2015) & $\longrightarrow$ & $0.19(0.15,0.23)$ & 11.41 \\
\hline Flores, $L(2012)$ & & $0.15(0.11,0.18)$ & 11.87 \\
\hline Subtotal (1-squared $=0.6 \%, p=0.419$ ) & & $0.16(0.13,0.18)$ & 60.16 \\
\hline & & & \\
\hline 212 months & & & \\
\hline Kleist, A. (2019) & & $0.14(0.06,0.21)$ & 8.45 \\
\hline Garcia-Morales, I. (2011) & & $0.13(0.05,0.22)$ & 7.61 \\
\hline MOG inty, R.N(2017). & $\rightarrow$ & $0.03(-0.00,0.06)$ & 11.96 \\
\hline Husain, A.(2012). & & $0.11(0.08,0.15)$ & 11.81 \\
\hline Subtotal (1-squared $=81.0 \%, p=0.001$ ) & & $0.10(0.04,0.16)$ & 39.84 \\
\hline & & & \\
\hline Overall (l-squared $=77.6 \%, p=0.000$ ) & & $0.13(0.09,0.16)$ & 100.00 \\
\hline NOTE: Weights are from random effects analysis & & & \\
\hline $\begin{array}{r}1 \\
-247\end{array}$ & & & \\
\hline
\end{tabular}

FIGURE 5 | Meta-analysis of withdraw rate due to adverse events. (A) Poole effect of withdraw rate due to adverse effects by study type. (B) Subgroup analysis of withdraw rate due to adverse effects in observational studies.

freedom in real-world studies. Further, seizure freedom for a long period of time (patients treated with $\mathrm{LCM} \geq 12$ months) was similar to that of 6-month of LCM adjunction. Altogether, these results suggested that the efficacy outcomes of LCM adjunction for real-world studies were similar or even better than that of randomized controlled, forced titration trials. In agreement with our findings, Villanueva et al. investigated a large series of patients with partial-onset seizures treated with LCM as early add-on therapy in clinical practice and revealed a 44.9
$\%$ of seizure free rate (32). More interestingly, in Villanueva's REALLY study, good efficacy of LCM monotherapy after success polytherapy in patients with partial-onset seizures was still observed (32).

There are some factors could affect the efficacy of LCM as an adjunctive treatment in adults with refractory epilepsy. Two of the observational studies included in our meta-analysis indicated that patients were more likely to achieve seizure control when LCM was used as first add-on, compared with a later 
treatment schedule $(22,26)$. In these two studies, the $50 \%$ responder rate and seizure free rate were particularly high in patients using LCM as a first add on medication. Similar findings were observed in Rung's study, in which seizure free rate was 57.8 and $27.8 \%$, respectively, and $50 \%$ response rate was 80.0 and $70.4 \%$, respectively, when LCM was used in treatment as the first and later therapy (second add-on) (33). In addition, different dosage of LCM used in these two trials could also affect the efficacy and safety for seizure in adults. Patients in real-world observational studies usually used a flexible dosing regimen, while patients in RCTs were titrated to a fixed dose regiment of LCM. Moreover, the efficacy of LCM may also be affected by the treatment of other AEDs. Fifty-percent responder rate in response to LCM adjunction progressively declined with increased number of prior AEDs treatment (34). In contrast to the observational studies, patients in RCTs had tried more AEDs before LCM adjunction, which may result in decline of the efficacy.

The incidences of AEs and withdraw rate due to AEs were pooled to assess the clinical safety of LCM as an adjunctive treatment. Our results showed that the pooled incidence of AEs (including serious and non-serious AEs) was 59\% in observational studies and $57 \%$ in RCTs, respectively. No significant difference between RCT and observational studies was observed. The most commonly reported AEs, which occurred in at least $10 \%$ of patients in any treatment group, focus on CNS and gastrointestinal systems (dizziness, headache, vomiting, diplopia and nausea) in RCT studies. Serious AEs, such as convulsion, dizziness, pyrexia, headache, diplopia, dysarthria, nausea, and vomiting, occurred in approximately $3-10 \%$ of all patients taking LCM in five RCT trials. Similar AEs including dizziness, diplopia, and ataxia, were also reported in observational studies. Serious AEs occurred in approximately $3-23.1 \%$ of all patients taking LCM in eleven observational studies. Although most AEs could lead to side effects $(31,35)$, they were nonspecific, and disappeared in some patients during the maintenance phase or with dose reduction. One observational showed that a skin rash occurred in one patient while titrating up LCM tablets, indicating an allergic reaction to a compound substance in LCM cannot be excluded (24). In addition, two patients lost more than $10 \%$ of their body weight after titration of LCM to $400 \mathrm{mg} /$ day. On a group level, body weight was not affected in the RCTs that evaluated LCM. However, $2 \%$ of patients experienced a greater than $10 \%$ decrease in body weight, but the mechanism remains unclarified (36). LCM has a different mechanism of action by selectively enhancing slow sodium channel inactivation, whereas traditional sodium blockers interfere with fast inactivation pathway of sodium channel (37). The AEs in LCM group may be contributed to the pharmacodynamic interaction between LCM and other AEDs. Several studies suggested that combining drugs that block voltage-dependent sodium channels (i.e., carbamazepine, lamotrigine and valproate) are more likely to lead to side effects $(22,27)$. Furthermore, a total $13 \%$ of patients were withdrawn from the trial prematurely due to AEs in RCTs; while discontinuation rates were 16 and $10 \%$ for 6 and 12-month treatment, respectively in real-word studies. Our findings suggested that LCM appeared to be relatively safe and well-tolerated for a long-term treatment. Taken together, these results provided confirmatory data on the safety and safety profile of adjunctive LCM in patients with refractory epilepsy. In addition, we recommend that a reduction of the dose of concomitant traditional sodium blockers might be useful to avoid AEs $(22,29)$. Moreover, using a flexible dosing of LCM based on the need of each patient is recommended as an effective method to obtain satisfactory seizure control and simultaneously minimizing AEs. Clinicians should be aware that weight loss may occur.

In the past decades, the third generation antiseizure medications including brivaracetam, perampanel, eslicarbazepine acetate (ESL), cenobamate and LCM have shown efficacy to reduce seizure frequency and are fairly well-tolerated in RCTs and real-world studies (38-43). Despite direct comparison of efficacy of treatment among those third generation antiseizure medications was still lacking, Brigo's research indicated that indirect comparison meta-analyses failed to a significant difference in efficacy between add-on ESL and LCM in patients with focal epilepsy (44). Direct head-to-head clinical trials are encouraged to compare the efficacy and safety of those third generation antiseizure medications in the future.

Although this meta-analysis provided useful information for clinician to treat patients with refractory epilepsy, the following limitations should be noted. 1) Our study included 11 realworld observational studies, and some of them contained a relatively small sample size. Therefore, pooled effects using random-effects meta-analysis with a small sample size may be less precise than that of large trials. 2) There was substantial heterogeneity among the included studies. Some factors could affect the efficacy of LCM as an adjunctive treatment in adults with refractory epilepsy, such as the different dosage of LCM and concomitant AEDs, the type of epilepsy, the number of concomitant AEDs, and the duration of epilepsy. These factors have a potential impact on the pooled results. Thus, additional clinical trials with large sample size and LCM added to monotherapy are needed to further explore the potential efficacy and safety of LCM for controlling seizures.

\section{CONCLUSIONS}

The results of the meta-analysis from RCTs and real-world observational studies confirmed that LCM is an effective and relatively safe drug when used as an adjunctive therapy in patients with refractory epilepsy. However, in many cases, patients unable to obtain satisfactory seizure remission by single AEDs are forced to take polytherapy, which could result in increase of the incidence of AEs. For these reasons, we recommend that combination of AEDs and other drugs with different mechanisms of action might be more efficacious and/or well-tolerated in patients. Otherwise, prospective reduction of concomitant sodium channels co-medications might be useful when combining with LCM to avoid AEs. Further trails are needed to assess the longer-term safety and efficacy of LCM as add-on treatment and as monotherapy. 


\section{DATA AVAILABILITY STATEMENT}

The original contributions presented in the study are included in the article/supplementary material, further inquiries can be directed to the corresponding author/s.

\section{AUTHOR CONTRIBUTIONS}

SL and QW conceived the study and wrote the paper. BP, LT, and DZ performed the literature search. JY and YW performed data extraction. LH analyzed and interpreted data. JZ gave critical comments and revised the manuscript.

\section{REFERENCES}

1. Spiciarich MC, von Gaudecker JR, Jurasek L, Clarke DF, Burneo J, Vidaurre J. Global health and epilepsy: update and future directions. Curr Neurol Neurosci Rep. (2019) 19:30. doi: 10.1007/s11910-019-0947-6

2. Billakota S, Devinsky O, Kim KW. Why we urgently need improved epilepsy therapies for adult patients. Neuropharmacology. (2019) 170:107855. doi: 10.1016/j.neuropharm.2019.107855

3. Kwan P, Arzimanoglou A, Berg AT, Brodie MJ, Allen Hauser W, Mathern G, et al. Definition of drug resistant epilepsy: Consensus proposal by the ad hoc Task Force of the ILAE Commission on Therapeutic Strategies Epilepsia. (2010) vol. 51. p. 1069-77. doi: 10.1111/j.1528-1167.2009.02397.x

4. French JA. Refractory epilepsy: clinical overview. Epilepsia. (2007) 48:3-7. doi: 10.1111/j.1528-1167.2007.00992.x

5. Perucca YU, Clincke E, Kirkpatrick GP. Lacosamide. Nat Rev Drug Discov. (2008) 7:973-4. doi: 10.1038/nrd2764

6. Rogawski MA, Tofighy A, White HS, Matagne A, Wolff C. Current understanding of the mechanism of action of the antiepileptic drug lacosamide. Epilepsy Res. (2015) 110:189-205. doi: 10.1016/j.eplepsyres.2014.11.021

7. Wilson SM, Khanna R. Specific binding of lacosamide to collapsin response mediator protein 2 (CRMP2) and direct impairment of its canonical function: implications for the therapeutic potential of lacosamide. Mol Neurobiol. (2014) 51:599-609. doi: 10.1007/s12035-014-8775-9

8. Sawh SC, Newman JJ, Deshpande S, Jones PM. Lacosamide adjunctive therapy for partial-onset seizures: a meta-analysis. PeerJ. (2013) 1:e114. doi: $10.7717 /$ peerj.114

9. Babar RK, Bresnahan R, Gillespie CS, Michael BD. Lacosamide add-on therapy for focal epilepsy. Cochrane Database Syst Rev. (2021) 5:Cd008841. doi: 10.1002/14651858.CD008841.pub3

10. McGinty RN, Costello DJ. Long-term lacosamide retention-Real-world experience at a tertiary epilepsy center in Ireland. Epilepsy Behav. (2017) 68:141-5. doi: 10.1016/j.yebeh.2016.10.029

11. Rocamora R, Ley M, Molins A, Toledo M, Sansa G, Bertol V, et al. Effect of lacosamide on depression and anxiety symptoms in patients with focal refractory epilepsy: a prospective multicenter study. Epilepsy Behav. (2018) 79:87-92. doi: 10.1016/j.yebeh.2017. 10.032

12. Konstantinos SC, Siontis C, Xiaoxi Y, Gersh BJ, Noseworthy PA. Do observational studies agree with randomized trials? Evaluation of oral anticoagulants in atrial fibrillation. J Am Coll Cardiol. (2020) 75:562-3. doi: 10.1016/j.jacc.2019.12.007

13. Liberati A, Altman DG, Tetzlaff J, Mulrow C, Gøtzsche PC, Ioannidis JP, et al. The PRISMA statement for reporting systematic reviews and metaanalyses of studies that evaluate health care interventions: explanation and elaboration. PLoS Med. (2009) 6:e1000100. doi: 10.1371/journal.pmed.10 00100

14. Higgins JP, Thompson SG, Deeks JJ, Altman DG. Measuring inconsistency in meta-analyses. BMJ. (2003) 327:557-60. doi: 10.1136/bmj.327.7414.557

\section{ACKNOWLEDGMENTS}

This work was supported by National Major Scientific and Technological Special Project for Significant New Drugs Development (2019zx09301102); the National Natural Sciences Foundation of Liaoning Province (2019MS-088; 2019-MS-077; 2020-MS-264); the Liaoning Revitalization Talents Program (XLYC1907026; XLYC1808031; XLYC2007151). We thank Dr. Baher Yar at Dalian Medical University for his helpful suggestions in editing this article.

15. Egger M, Davey Smith G, Schneider M, Minder C. Bias in metaanalysis detected by a simple, graphical test. BMJ. (1997) 315:629-34. doi: 10.1136/bmj.315.7109.629

16. Ioannidis JP. Interpretation of tests of heterogeneity and bias in meta-analysis. J Eval Clin Pract. (2008) 14:951-7. doi: 10.1111/j.1365-2753.2008.00986.x

17. Ben-Menachem E, Biton V, Jatuzis D, Abou-Khalil B, Doty P, Rudd GD. Efficacy and safety of oral lacosamide as adjunctive therapy in adults with partial-onset seizures. Epilepsia. (2007) 48:1308-17. doi: 10.1111/j.1528-1167.2007.01188.x

18. Hong Z, Inoue Y, Liao W, Meng H, Wang X, Wang W, et al. Efficacy and safety of adjunctive lacosamide for the treatment of partial-onset seizures in Chinese and Japanese adults: a randomized, double-blind, placebo-controlled study. Epilepsy Res. (2016) 127:267-75. doi: 10.1016/j.eplepsyres.2016. 08.032

19. Halász P, Kälviäinen R, Mazurkiewicz-Beldzińska M, Rosenow F, Doty P, Hebert D, et al. Adjunctive lacosamide for partial-onset seizures: efficacy and safety results from a randomized controlled trial. Epilepsia. (2009) 50:443-53. doi: 10.1111/j.1528-1167.2008.01951.x

20. Chung S, Sperling MR, Biton V, Krauss G, Hebert D, Rudd GD, et al. Lacosamide as adjunctive therapy for partial-onset seizures: a randomized controlled trial. Epilepsia. (2010) 51:958-67. doi: 10.1111/j.1528-1167.2009.02496.x

21. Wu XT, Sun HB, Wang WM, Lin WH, Yan CZ, Li XH, et al. Efficacy and safety of Lacosamide as adjunctive treatment for partial-onset seizures. $J$ Epilepsy. (2015) 1:5-16.

22. Stephen LJ, Kelly K, Parker P, Brodie MJ. Adjunctive lacosamide in clinical practice: sodium blockade with a difference? Epilepsy Behav. (2011) 22:499504. doi: 10.1016/j.yebeh.2011.07.035

23. Maschio M, Zarabla A, Maialetti A, Fabi A, Vidiri A, Villani V, et al. Quality of life, mood and seizure control in patients with brain tumor related epilepsy treated with lacosamide as add-on therapy: a prospective explorative study with a historical control group. Epilepsy Behav. (2017) 73:83-9. doi: 10.1016/j.yebeh.2017.05.031

24. Wehner T, Bauer S, Hamer HM, Hattemer K, Immisch I, Knake S, et al. Six months of postmarketing experience with adjunctive lacosamide in patients with pharmacoresistant focal epilepsy at a tertiary epilepsy center in Germany. Epilepsy Behav. (2009) 16:423-5. doi: 10.1016/j.yebeh.2009.07.043

25. IJff DM, van Veenendaal TM, Majoie HJ, Louw AJde, Jansen JF, Aldenkamp AP. Cognitive effects of lacosamide as adjunctive therapy in refractory epilepsy. Acta Neurol Scand. (2015) 131:347-54. doi: 10.1111/ane.12372

26. Zadeh WW, Escartin A, Byrnes W, Tennigkeit F, Borghs S, Li T, et al. Efficacy and safety of lacosamide as first add-on or later adjunctive treatment for uncontrolled partial-onset seizures: a multicentre open-label trial. Seizure. (2015) 31:72-9. doi: 10.1016/j.seizure.2015.07.001

27. Flores L, Kemp S, Colbeck K, Moran N, Quirk J, Ramkolea P, et al. Clinical experience with oral lacosamide as adjunctive therapy in adult patients with uncontrolled epilepsy: a multicentre study in epilepsy clinics in the United Kingdom (UK). Seizure. (2012) 21:512-7. doi: 10.1016/j.seizure.2012.05.005 
28. Husain A, Chung S, Faught E, Isojarvi J, McShea C, Doty P. Long-term safety and efficacy in patients with uncontrolled partial-onset seizures treated with adjunctive lacosamide: results from a Phase III open-label extension trial. Epilepsia. (2012) 53:521-8. doi: 10.1111/j.1528-1167.2012.03407.x

29. Kleist A, Kerling F, Hamer H, Winterholler M. Lacosamide in patients with intellectual disability and refractory epilepsy. Acta Neurol Belg. (2019) 119:423-30. doi: 10.1007/s13760-01901098-3

30. García-Morales I, Delgado RT, Falip M, Campos D, García ME, Gil-Nagel A. Early clinical experience with lacosamide as adjunctive therapy in patients with refractory focal epilepsy and nocturnal seizures. Seizure. (2011) 20:801-4. doi: 10.1016/j.seizure.2011.08.005

31. Chen D, Lin Y, Chen T, Zhang Q, Lin Y, Si Y, et al. Dose effects of lacosamide as add-on therapy for partial-onset seizure in adult. Neurol Sci. (2016) 37:907-20. doi: 10.1007/s10072-016-2512-2

32. Villanueva V, Garcés M, López-Gomáriz E, Serratosa JM, González-Giráldez, B, et al. Early add-on lacosamide in a real-life setting: results of the REALLY study. Clin Drug Investig. (2015). 35:121-31. doi: 10.1007/s40261-0140255-5

33. Runge U, Arnold S, Brandt C, Reinhardt F, Kühn F, Isensee K, et al. A noninterventional study evaluating the effectiveness and safety of lacosamide added to monotherapy in patients with epilepsy with partial-onset seizures in daily clinical practice: the VITOBA study. Epilepsia. (2015) 56:1921-30. doi: 10.1111/epi.13224

34. Brodie MJ, Kelly K, Stephen LJ. Prospective audits with newer antiepileptic drugs in focal epilepsy: insights into population responses? Epilepsy Behav. (2014) 31:73-6. doi: 10.1016/j.yebeh.2013. 11.016

35. Zaccara G, Giovannelli F, Maratea D, Fadda V, Verrotti A. Neurological adverse events of new generation sodium blocker antiepileptic drugs. Metaanalysis of randomized, double-blinded studies with eslicarbazepine acetate, lacosamide and oxcarbazepine. Seizure. (2013) 22:528-36. doi: 10.1016/j.seizure.2013.03.016

36. Doty P, Rudd GD, Stoehr T, Thomas D. Safety and tolerability of lacosamide: a summary of adverse events in epilepsy clinical trials. In: Poster presented at the 61st annual American Academy of Neurology Meeting Seattle, WA, April 2009. (2009).

37. Brodie MJ, Sills GJ. Combining antiepileptic drugs-rational polytherapy? Seizure. (2011) 20:369-75. doi: 10.1016/j.seizure.2011.01.004

38. Lattanzi S, Cagnetti C, Foschi N, Provinciali L, Silvestrini M. Brivaracetam add-on for refractory focal epilepsy: a systematic review and metaanalysis. Neurology. (2016) 86:1344-52. doi: 10.1212/WNL.00000000000 02545
39. Lattanzi S, Canafoglia L, Canevini MP, Casciato S, Chiesa V, Dainese F, et al. Adjunctive brivaracetam in focal epilepsy: real-world evidence from the BRIV Aracetam add-on First Italian Network Study (BRIVAFIRST). CNS Drugs. (2021). doi: 10.1007/s40263-021-00856-3

40. Hsu WW, Sing CW, He Y, Worsley AJ, Wong IC, Chan EW. Systematic review and meta-analysis of the efficacy and safety of perampanel in the treatment of partial-onset epilepsy. CNS Drugs. (2013) 27:817-27. doi: 10.1007/s40263-013-0091-9

41. Zhang R, Qiao S, Fang X, Wang K, Shi Y, Du Q, et al. Efficacy and tolerability of perampanel as adjunctive therapy in Chinese patients with focal-onset seizures: an observational, prospective study. Front Neurol. (2021) 12:731566. doi: 10.3389/fneur.2021.731566

42. Lattanzi S, Brigo F, Cagnetti C, Verrotti A, Zaccara G, Silvestrini M. Eslicarbazepine acetate in the treatment of adults with partial-onset epilepsy: an evidence-based review of efficacy, safety and place in therapy. Core Evid. (2018) 13:21-31. doi: 10.2147/CE.S142858

43. Lattanzi S, Trinka E, Zaccara G, Striano P, Del Giovane C, Silvestrini $\mathrm{M}$, et al. Adjunctive cenobamate for focal-onset seizures in adults: a systematic review and meta-analysis. CNS Drugs. (2020) 34:1105-20. doi: 10.1007/s40263-020-00759-9

44. Brigo F, Trinka E, Bragazzi NL, Nardone R, Milan A, Grillo E. A common reference-based indirect comparison meta-analysis of eslicarbazepine versus lacosamide as add on treatments for focal epilepsy. Epilepsy Res. (2016) 127:12-8. doi: 10.1016/j.eplepsyres.2016.08.006

Conflict of Interest: The authors declare that the research was conducted in the absence of any commercial or financial relationships that could be construed as a potential conflict of interest.

Publisher's Note: All claims expressed in this article are solely those of the authors and do not necessarily represent those of their affiliated organizations, or those of the publisher, the editors and the reviewers. Any product that may be evaluated in this article, or claim that may be made by its manufacturer, is not guaranteed or endorsed by the publisher.

Copyright (c) 2021 Hou, Peng, Zhang, Yang, Wang, Tong, Li, Wang and Zhao. This is an open-access article distributed under the terms of the Creative Commons Attribution License (CC BY). The use, distribution or reproduction in other forums is permitted, provided the original author(s) and the copyright owner(s) are credited and that the original publication in this journal is cited, in accordance with accepted academic practice. No use, distribution or reproduction is permitted which does not comply with these terms. 